\title{
MODELLING EXTREME WAVE EVENTS (PRESENT AND FUTURE SCENARIOS) IN SOUTHWEST ENGLAND
}

\author{
Jose M. Horrillo-Caraballo, Shunqi Pan ${ }^{2}$, Dominic E. Reeve ${ }^{1}$, Dave Simmonds ${ }^{3}$, Deborah \\ Greaves $^{3}$ and Andrew Fox ${ }^{3}$
}

\begin{abstract}
Coastal areas are vital part of the local economies in terms of population, tourism, trade, industry only to mention a few sectors. As the economy in these coastal areas develops, the risk in which the assets are based will increase as well as the likelihood of extreme events. The European project THESEUS "Innovative coastal technologies for safer European coasts in a changing climate" was conceived with the idea of tackle these and to reduce coastal risks. In this paper we will present a detailed study of the results obtained with the model and how this can affect the area of the Teign estuary under the future climate scenarios and the sea level rise expected. In particular the importance (or otherwise) of the joint extreme occurrence of large waves and high surge.
\end{abstract}

Keywords: extreme wave events; Theseus project; POLCOMS; modelling

\section{INTRODUCTION}

Coastal areas are vital part of the local economies in terms of population, tourism, trade, industry only to mention a few sectors. There are many costal problems related to these sectors. As the economy in these coastal areas develops, the risk in which the assets are based will increase as well as the likelihood of extreme events will increase. Existing coastal management and defence methods are not well adjusted to these tasks as they assume a stationary condition. The European project THESEUS "Innovative coastal technologies for safer European coasts in a changing climate" was conceived with the idea of tackle these and use European and international experience in applying innovative technologies to reducing coastal risks. THESEUS is a multidisciplinary project using 8 study site across Europe in which the southwest coast of England is included as a study site.

In this study site, climate present conditions and future conditions were modelled using the software POLCOMS, (Proudman Oceanographic Laboratory Coastal Ocean Modelling System). This baroclinic 3D model with the ability to run in regions, which include both the deep ocean and the continental shelf, is coupled with a wave model ProWAM (Osuna et al. 2004). The model was run with 2-level nested grids, with the results from the coarse grid being used to provide the boundary conditions to the fine grid. Wind field and atmospheric pressure were used as surface forcing.

The main aim of this study was to generate wave and surge considers for present conditions (19702009 or 1990's) and for three scenarios: short (2010-2039 or 2020's), mid (2040-2069 or 2050's) and long-term (2070-2099 or 2080's) scenarios, so that coastal flooding hazard maps (for different return periods) can be generated and also the short, mid and long-term erosion patterns can be determined.

Wave and surge data were obtained from the POLCOMS/ProWAM model, which was set up with nested grids centred at the study area. Model has been extensively tested and validated in the area (Chen et al. 2010). The present and future wave and surge conditions were modelled using POLCOMS for one of the IPCC greenhouse gas emission scenarios: A1B (IPCC AR4 2007) at the study site and using the wind and sea level pressure (SLP) from Max Planck Institute for Meteorology WDCC/CERA database (WDCC 2009). In general, the extremes were calculated by fitting the annual maxima to a selection of candidate probability distribution functions. The 1 year lag correlation was calculated to ensure statistical independence within the time series. Given the time-limited extent of the data sets, bootstrapping was used to re-sample the data and generate confidence limits based on the re-sampled populations following the methods described in Reeve (1996) and Li et al. (2008).

\section{STUDY SITE}

The Plymouth Sound to Exe Estuary site is located in southwest England (Figure 1a), encompassing a $100 \mathrm{~km}$ stretch of coastline bordered by the English Channel. The site is one of the most diverse coastal settings in Europe and incorporates a range of habitats from exposed rocky and shingle coast to sheltered mud of flooded valleys or 'rias' together with densely populated urbanised and industrial zones of Plymouth Sound, Torbay and Exeter. It is, therefore, an appropriate site to study as it

\footnotetext{
${ }^{1}$ College of Engineering, Swansea University, Singleton Park, Swansea, SA2 8PP, Wales, UK

2 School of Engineering, Cardiff University, The Parade, Cardiff, CF24 3AA, Wales, UK

${ }^{3}$ School of Marine Science and Engineering, Plymouth university, Drake Circus, Plymouth, PL4 8AA, UK
} 
involves: complex coastal and estuarine processes; interactions between coastal defence structures and coastal morphology; and significant economic, social and environmental impacts.

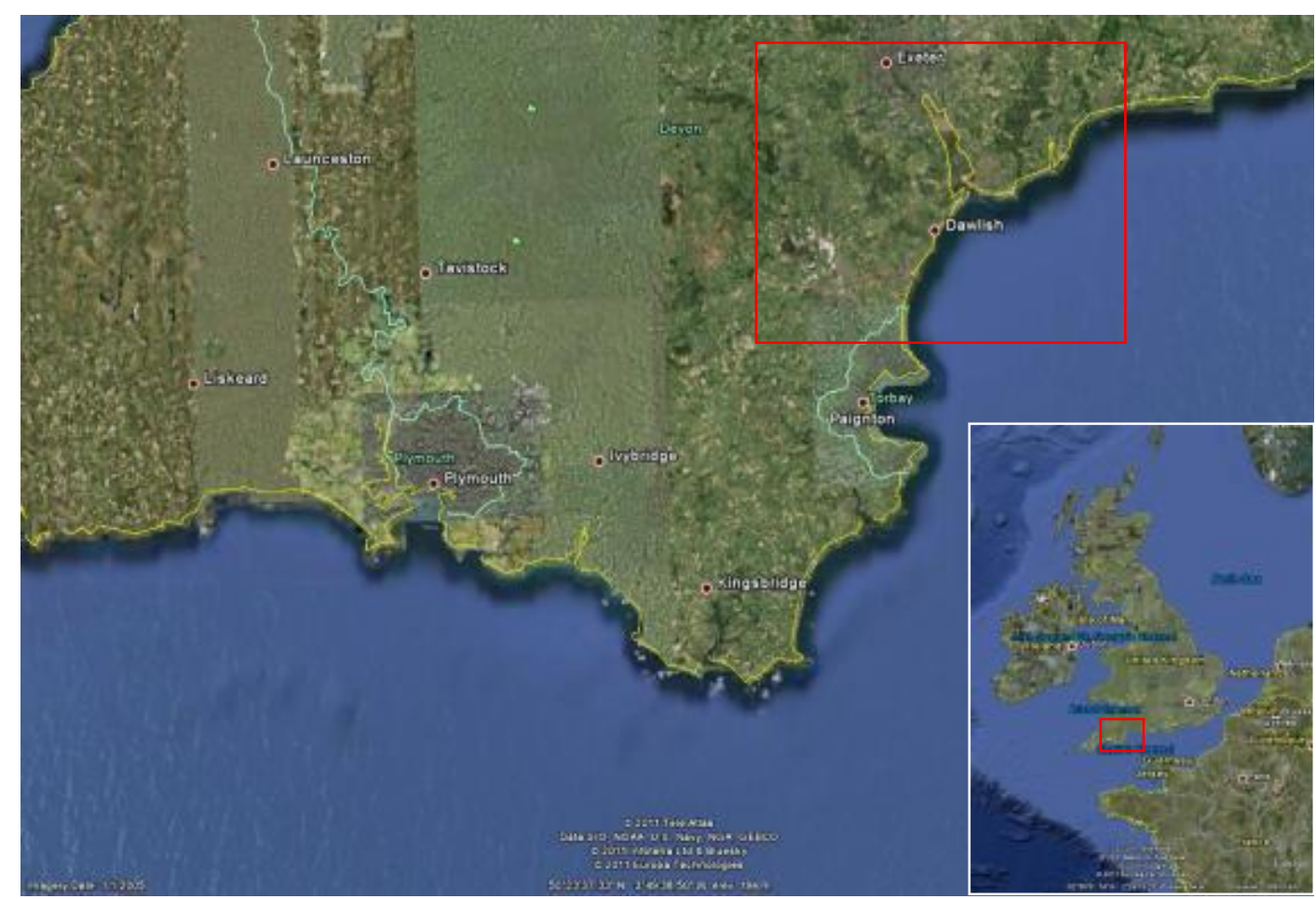

(a) Plymouth Sound to Exe Estuary

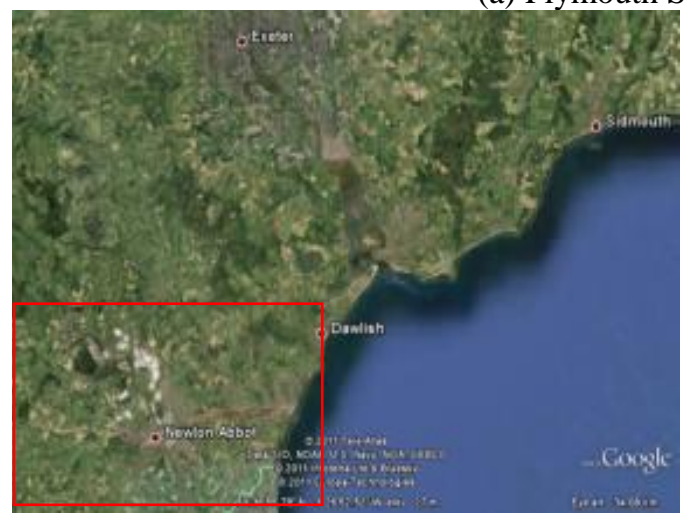

(b) Exe and Teign Estuaries

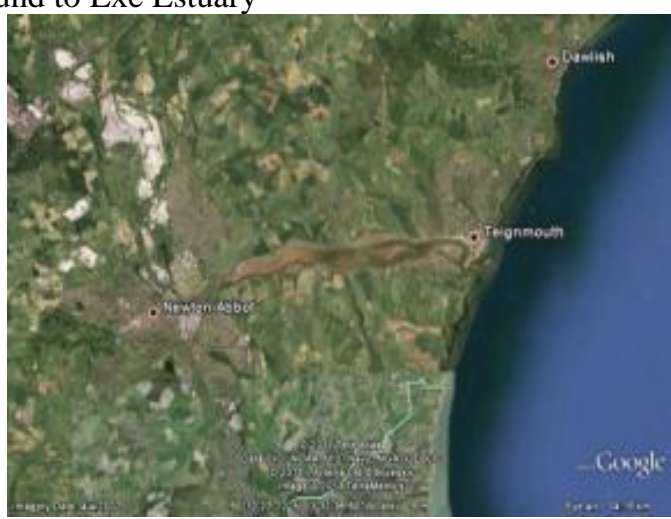

(c) Teign Estuary

Figure 1. Study site - Plymouth Sound to Exe Estuary.

Within the study site, we focus first at the medium scale on the Exe Estuary to Teign Estuary section (Figure 1b), and then in detail on the Teign Estuary itself (Figure 1c). A major modifier of the coastline is the railway line, which was started by the South Devon Railway Company, running from Exeter St Davids to Teignmouth in 1846 and later extended to Newton Abbot. It has since become part of the mainline rail network linking the southwest to London, and beyond. The railway line occupies considerable stretches of coastal frontage (Exeter to Dawlish to Teignmouth to Newton Abbot), and Network Rail (Network Rail runs, maintains and develops Britain's tracks, signalling system, rail bridges, tunnels, level crossings, viaducts and 18 key stations) has responsibility for the sea defences along those sections that protect the railway infrastructure. Coastal defence work to protect the railway line has had an impact on coastal processes. Pressures also include physical disturbance, for example by trampling, dredging, fishing, land reclamation and adjacent coastal development through the construction of sea defences, as well as the potential for changes in the hydrological regime.

Due to the South-West main railway line at the Exmouth site, and other permanent coastal defence structures, such as seawalls and groynes, the coastline position has not been altered significantly. 
However, beach profiles at the various locations have significant alternations under the storm conditions. Figure 2 shows some examples of the historical damages caused by flooding events in 2004 in the study area.
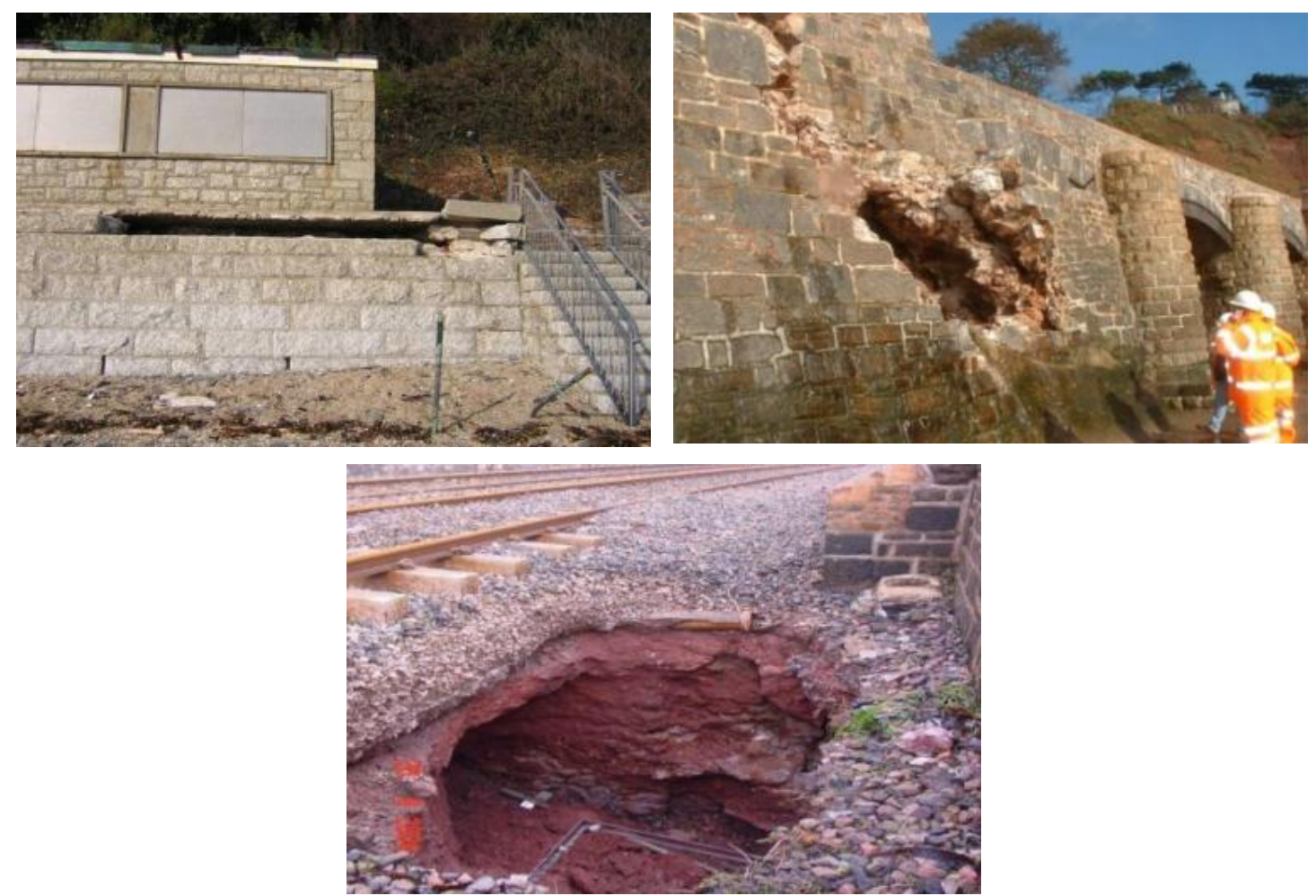

Figure 2. Damage due to wave overtopping to the seawall (top panels) and damage due to wave overtopping and flooding to the South-West main railway line (bottom panel).

\section{MODELLING SYSTEM}

This study uses the coupled POLCOMS/ProWAM modelling system with 2 nested grids. This modelling system has been extensively calibrated and used in many applications (Osuna et al. 2004; Pan et al. 2009a; Pan et al. 2009b; Chen et al. 2010). Only a brief description of these models is given here.

WAM is a third generation spectral wave model, which solves the wave action balance equation without any pre-defined shape of the energy spectrum (Günther et al. 1992). ProWAM is a modified version of WAM (Monbaliu et al. 2000) which also includes the current effects on wave modelling.

POLCOMS is a baroclinic 3D-current model with coverage of both the deep ocean and the continental shelf, developed at Proudman Oceanographic Laboratory (now National Oceanography Centre - NOC) (Holt and James 2001). This model incorporates the third generation wave model, ProWAM, with an option of two-way coupling to quantitatively predict waves and currents (Flather 1981; Wolf et al. 2002; Osuna et al. 2004). The model has been widely used to generate tides and surge for both the deep ocean and the continental shelf. Together with coupled ProWAM model as described above, the model also includes the interaction between waves and currents.

\section{Model Setup}

In order to examine the effects of the winds and waves in the area of the Plymouth Sound to the Exe estuary, two computational domains were used in the present study and they are shown in Figure 3; the largest computational domain covers a significant part of north-eastern Atlantic Ocean with a grid resolution of $1 / 10^{\circ}$ by $1 / 10^{\circ}$ (coarse grid). The second grid (fine grid) level covers part of south-west water adjacent to the Cornish Peninsula with a further reduced grid size at the resolution of $1 / 60^{\circ}$ by $1 / 60^{\circ}$, which is the smallest computational domain in this study. A one-way downscaling technique from the largest domain to the smallest domain was adopted. The hydrodynamics boundary conditions 
for the smaller domain are provided by the model results from the up-level coarser domain runs. Figure 3 shows the relative positions of the nested computational domains.

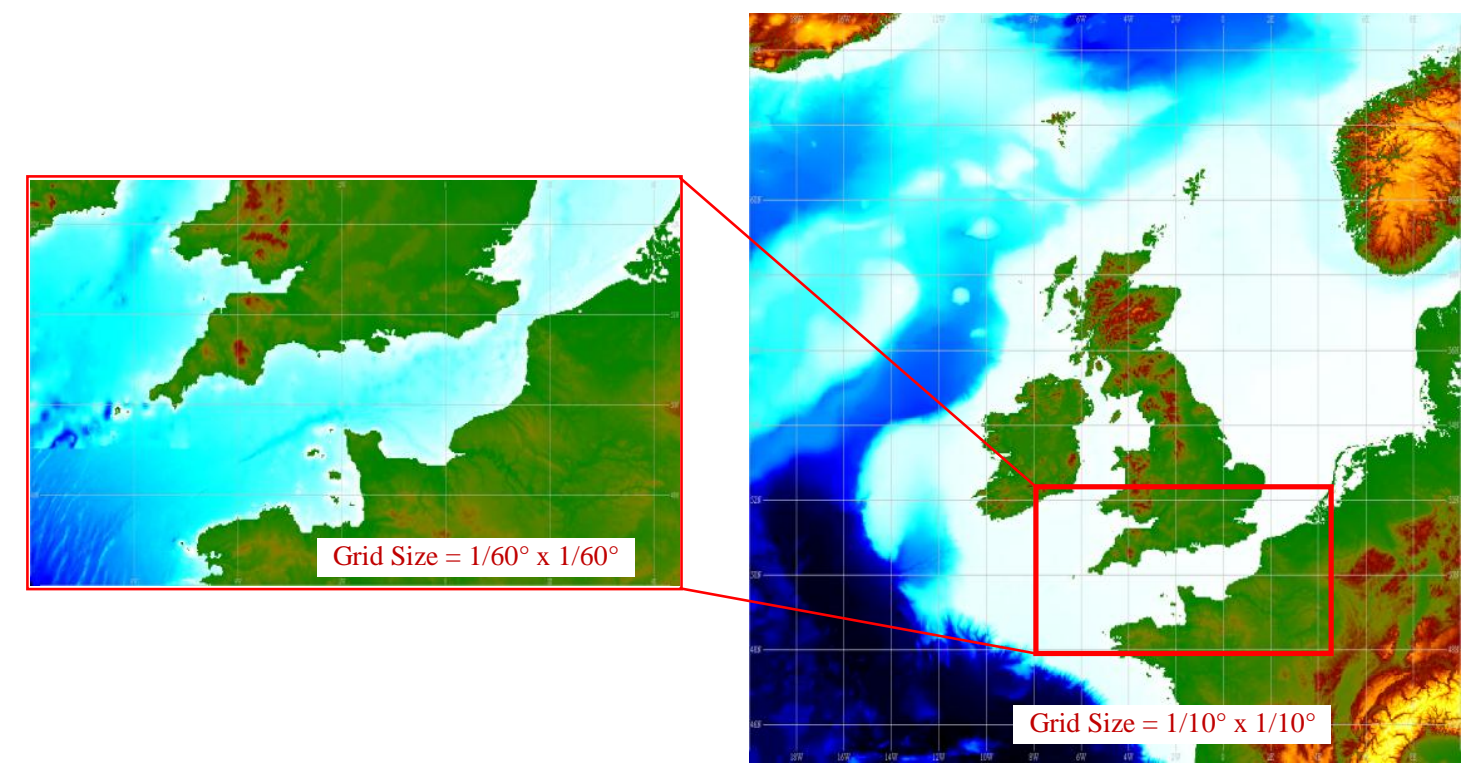

Figure 3. Computational domain for POLCOMS/ProW AM. Nested domains.

Figure 4 shows a snapshot for the significant wave height and for the surge in the coarse grid domain and the area of the study site.

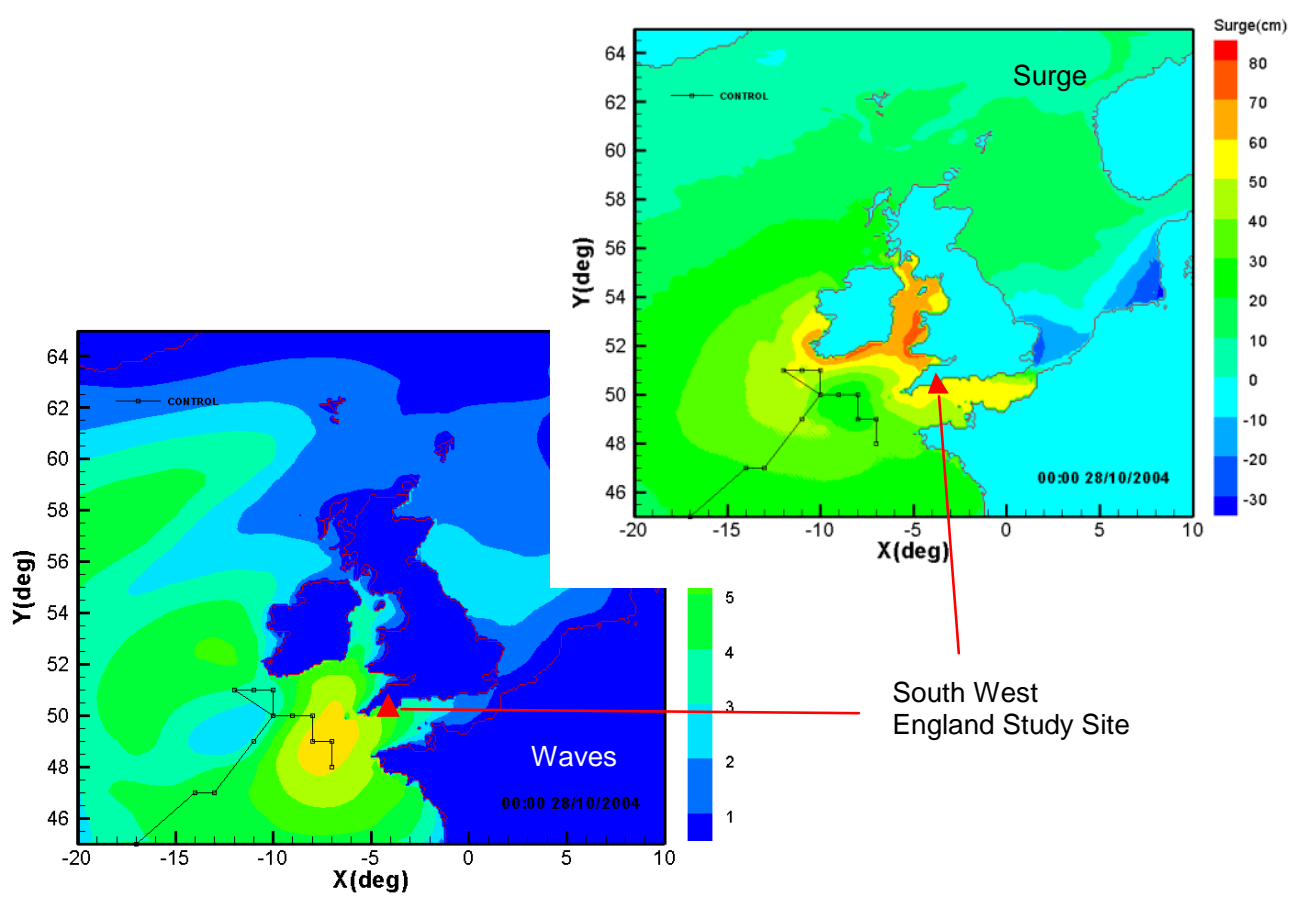

Figure 4. Snapshot of the computed significant wave height and surge in the area of the study site.

\section{METHODS}

After running the model for the site study, (nested model), waves were calculated for each of the climate scenarios (present, short-, mid-, and long-term). For each of these climate scenarios, significant wave height were calculated every hour for each year and then the maximum wave height for each year was taken. Then, the extremes were calculated by fitting the annual maxima to a selection of candidate probability distribution functions. The 1 year lag correlation was calculated to ensure statistical 
independence within the time series. Given the time-limited extent of the data sets, bootstrapping was used to re-sample the data and generate confidence limits based on the re-sampled populations following the methods described in Reeve (1996) and $\mathrm{Li}$ et al. (2008).

Given several years of wave height data, the typical approach to find the return period of extreme wave, is to extract annual maximum wave heights and then find a possible cumulative density function (CDF) that fit to the data. There are different types of CDF that can fit to the data and they vary in form and typically have two or three parameters. Once the CDF parameters have been optimised against the wave statistics, the CDFs are used to estimate the return period values for the wave heights. In this study we follow the approach of Reeve (1996) and Li et al. (2008).

Resampling the data is a good approach for defining a consistent measure of goodness of fit, that is, to create new samples from the original sample. The resampling techniques allow investigating the stability or uncertainty of the performance of the fitted CDF and at the same time can provide an estimation of the uncertainty of the extreme values. But it must be taken into account that resampling methods do not create new information, it only allows to investigate the statistics of the original data. By resampling with omission and/or repetition of the original sample, the stability of the statistical parameters derived from the observations can be determined. For this study, the method used is bootstrapping. The bootstrap resampling is a computer-intensive method that has been available for more than 20 years (Efron, 1979), but has only recently become more widely used with advances in computing power.

\section{RESULTS AND DISCUSSIONS}

The future scenarios were considered according to IPCC suggested greenhouse gas emission models A1B (IPCC AR4 2007), and the wind and sea level pressure (SLP) data from Max Planck Institute for Meteorology WDCC/CERA database (WDCC 2009). One time slice from 1970-2000 and three time slices from 2010 to 2100 were modelled. Figure 5 shows the yearly maxima of the significant wave heights at Plymouth and Exmouth, together with the present wave conditions.
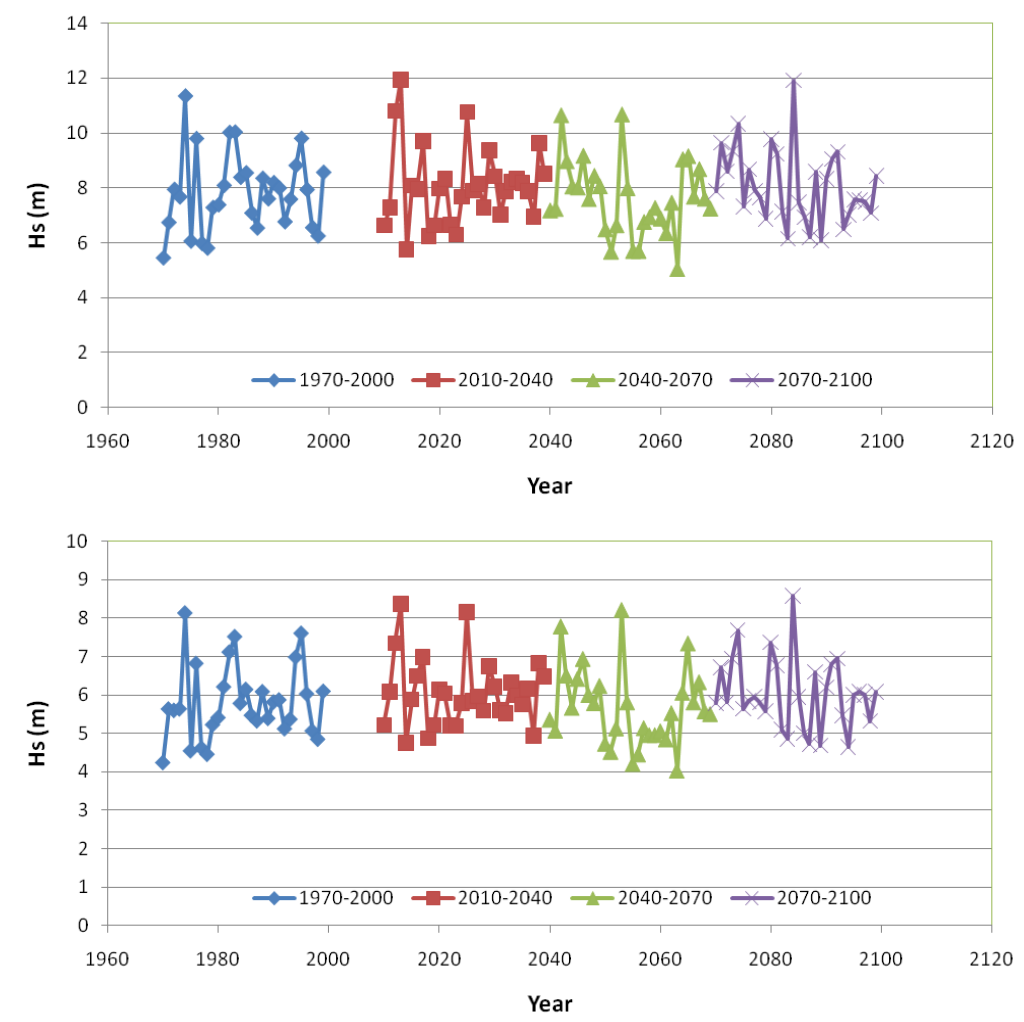

Figure 5. Yearly maxima of significant wave height at Plymouth (top panel) and Exmouth (bottom panel) for the four time slices (present, short-, mid- and long-term conditions).

The mean significant wave heights at Plymouth and Exmouth for the three future time slices, together with those for the present conditions are shown in Figure 6. At both locations, the mean 
significant wave heights under A1B scenarios for future time slices exhibit a cyclic pattern. The wave heights for the periods of 2010-2040 and 2070-2100 are higher than that at present conditions, but the wave height during 2040-2070 is lower than the present wave height.

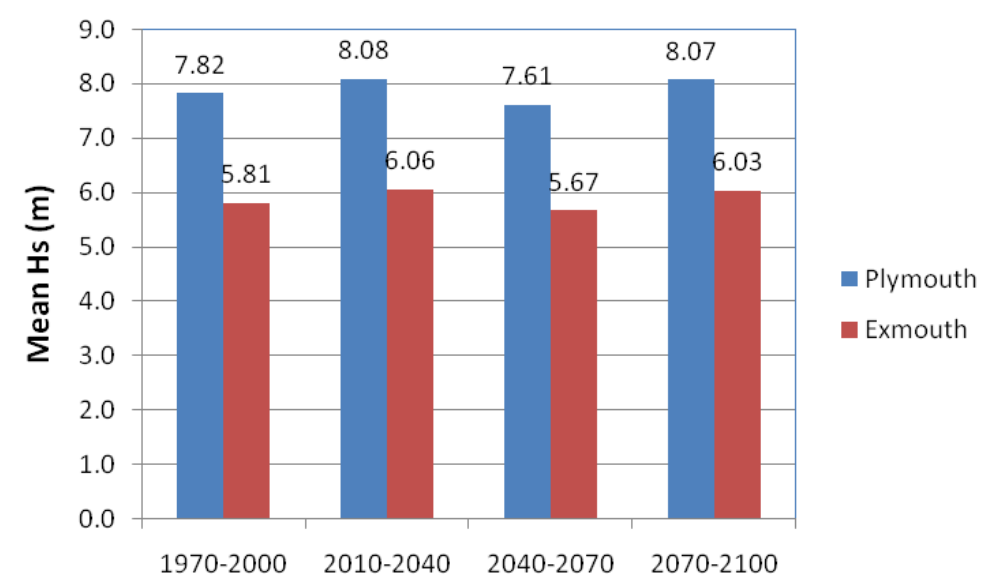

Figure 6. Mean significant wave heights at Plymouth and Exmouth for present condition and for the three future time slices (short-, mid- and long-term).

Analysing the wave directions for the present and future climate scenarios (Figure 7), these wave roses for each of the scenarios does not alter in a great scale the direction between there. Taking into account the wave roses detailed in Figure 7, the areas in the Teign and in the Exe estuaries that suffer erosion or accretion in the present conditions will continue suffering erosion or accretion during the future climate scenario conditions. That is to say that the areas that are eroded or accreted in the present conditions will be eroded or accreted during the future condition in a lesser or a greater degree that the ones that they are suffering in the present condition.

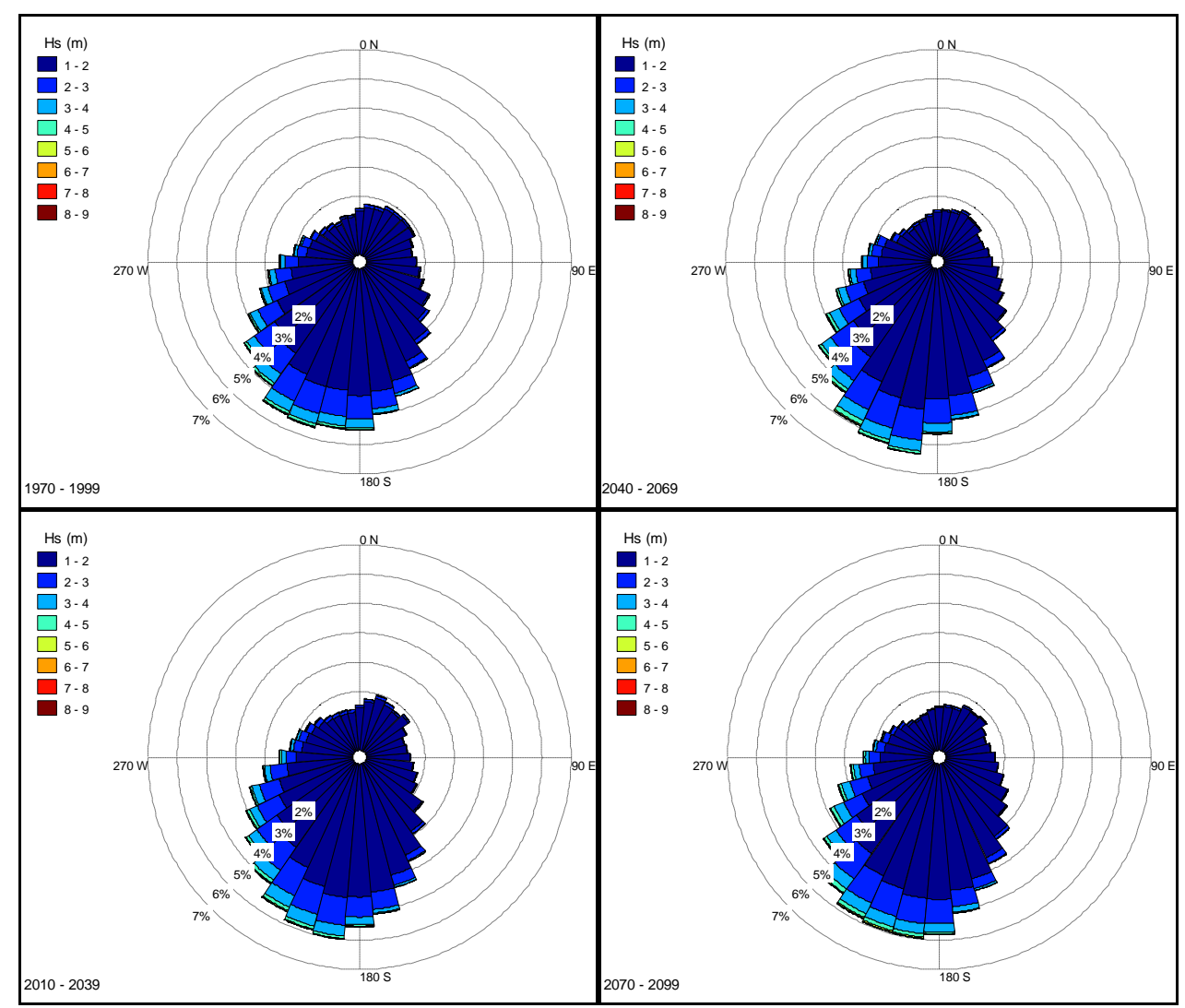

Figure 7. Exmouth wave roses for the different climate scenarios (Present, short-term, mid-term and longterm). 
The joint wave and surge distributions for the three future scenarios (short-, mid- and long-term) are shown in Figure 8 for Exmouth and Figure 9 for Plymouth. The distribution shapes are very similar, indicating insignificant changes for the A1B greenhouse gas emission scenario.
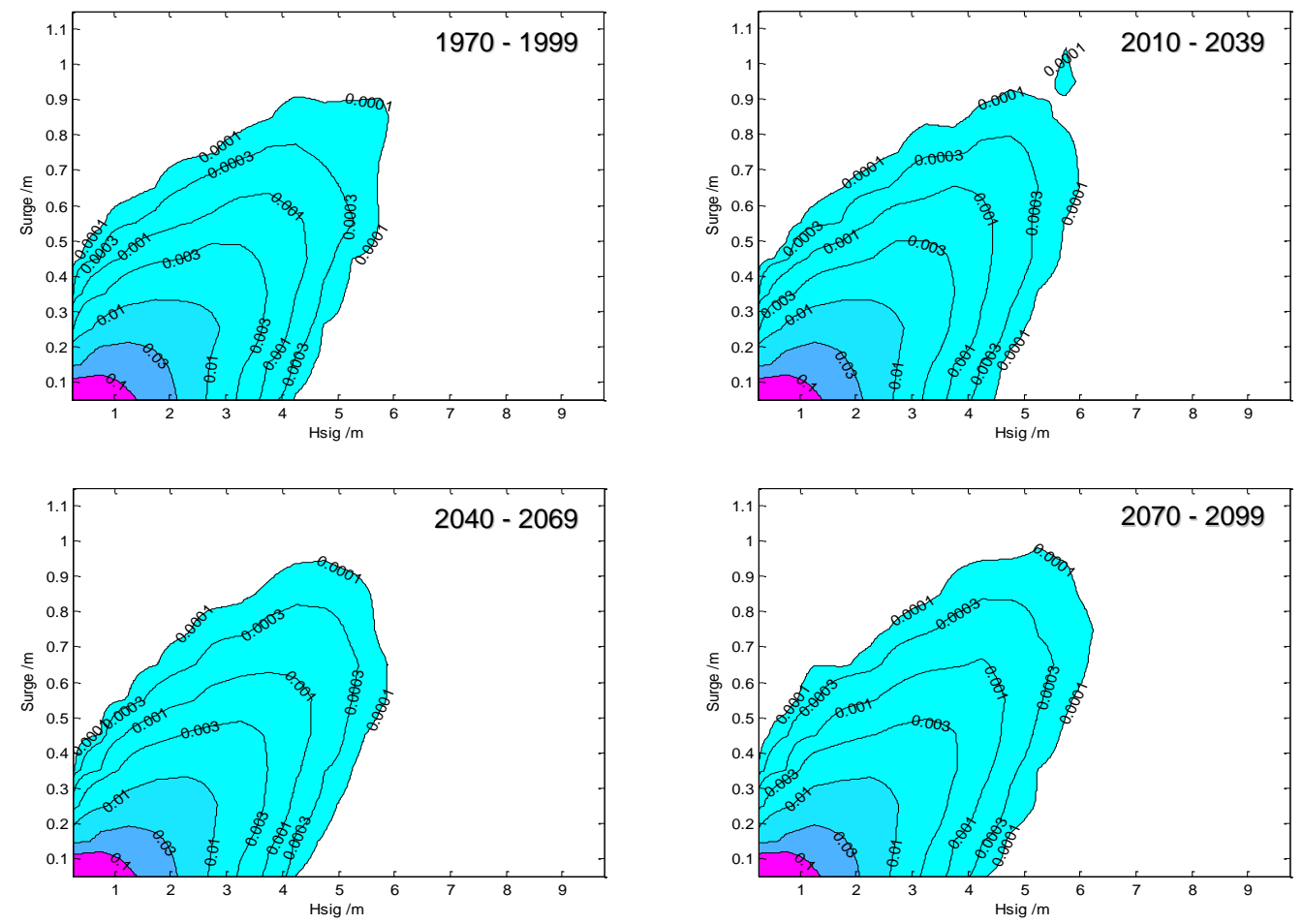

Figure 8. Joint wave and surge distributions: contours (in log scale) at Exmouth for future scenarios. Present (top left panel), Short-term (top right panel), mid-term (bottom left panel) and long-term (bottom right panel).
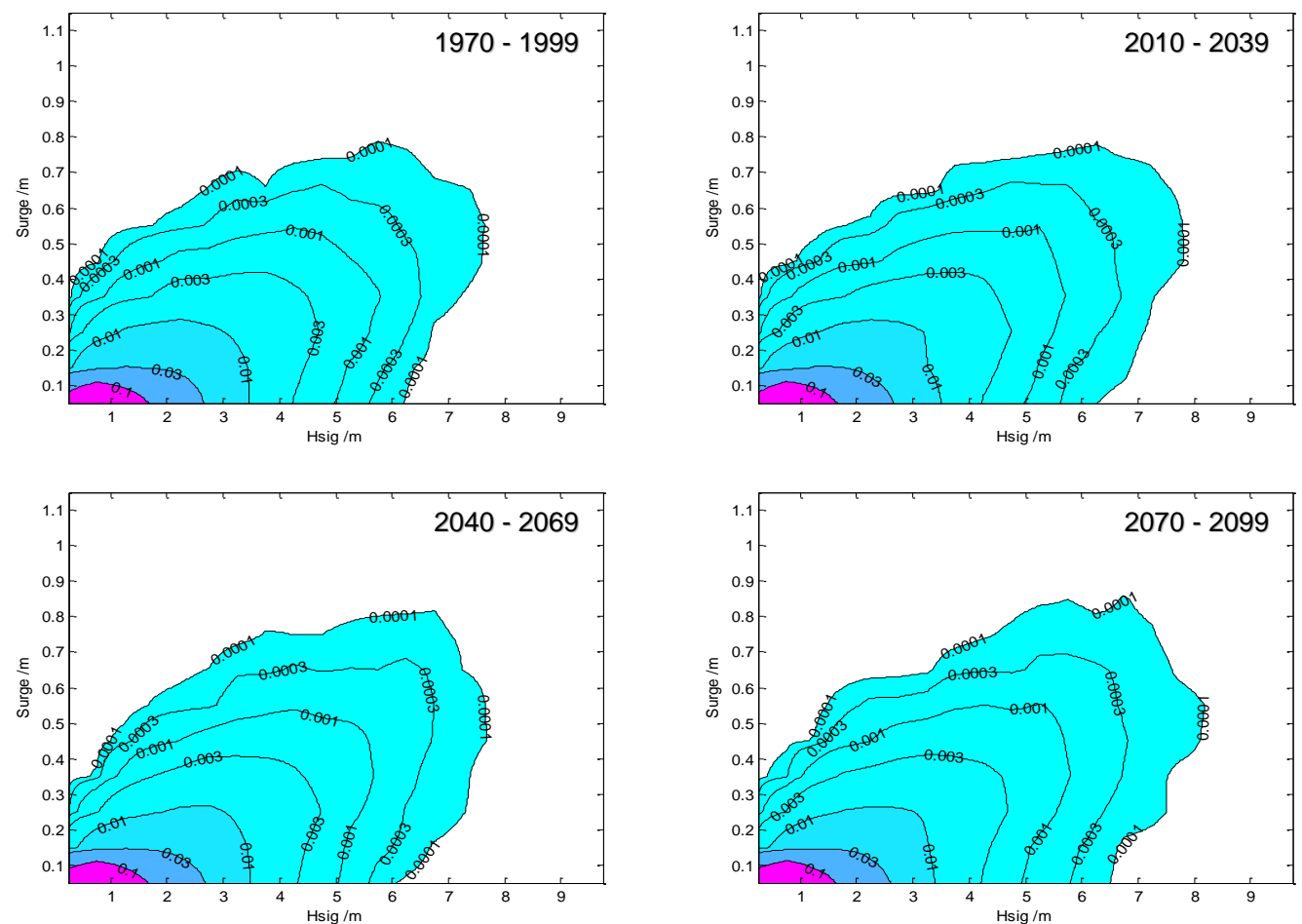

Figure 9. Joint wave and surge distributions: contours (in log scale) at Plymouth for future scenarios. Present (top left panel), Short-term (top right panel), mid-term (bottom left panel) and long-term (bottom right panel). 
The predicted extreme significant wave heights at Plymouth for each of the time slices (1970-1999 for present conditions; 2010 -2039 for short-term; 2040-2069 for mid-term; and 2070-2099 for longterm climate scenarios) are shown in Table 1. Table 2 shows the predicted extreme significant wave height and the corresponding return period for Exmouth.

\begin{tabular}{|c|c|c|c|c|}
\hline $\begin{array}{c}\text { Return } \\
\text { Period }(\mathrm{Y})\end{array}$ & $1970-2000$ & $2010-2040$ & $2040-2070$ & $2070-2100$ \\
\hline 2 & 7.668 & 7.923 & 7.458 & 7.923 \\
\hline 5 & 9.085 & 9.358 & 8.827 & 9.277 \\
\hline 10 & 10.029 & 10.314 & 9.739 & 10.179 \\
\hline 20 & 10.936 & 11.232 & 10.615 & 11.046 \\
\hline 50 & 12.111 & 12.422 & 11.750 & 12.169 \\
\hline 100 & 12.991 & 13.314 & 12.601 & 13.011 \\
\hline 200 & 13.868 & 14.202 & 13.449 & 13.850 \\
\hline 500 & 15.026 & 15.375 & 14.567 & 14.956 \\
\hline 1000 & 15.901 & 16.261 & 15.412 & 15.793 \\
\hline 2000 & 16.776 & 17.147 & 16.257 & 16.629 \\
\hline
\end{tabular}

\begin{tabular}{|c|c|c|c|c|}
\hline $\begin{array}{c}\text { Return } \\
\text { Period }(\mathrm{Y})\end{array}$ & $1970-2000$ & $2010-2040$ & $2040-2070$ & $2070-2100$ \\
\hline 2 & 5.703 & 5.960 & 5.558 & 5.930 \\
\hline 5 & 6.666 & 6.835 & 6.555 & 6.858 \\
\hline 10 & 7.308 & 7.418 & 7.220 & 7.476 \\
\hline 20 & 7.924 & 7.978 & 7.858 & 8.070 \\
\hline 50 & 8.723 & 8.703 & 8.685 & 8.840 \\
\hline 100 & 9.322 & 9.247 & 9.305 & 9.417 \\
\hline 200 & 9.918 & 9.789 & 9.922 & 9.991 \\
\hline 500 & 10.705 & 10.504 & 10.737 & 10.749 \\
\hline 1000 & 11.300 & 11.044 & 11.353 & 11.323 \\
\hline 2000 & 11.895 & 11.584 & 11.969 & 11.895 \\
\hline
\end{tabular}

\section{CONCLUSIONS}

- The highest surge level is about $1 \mathrm{~m}$ at Plymouth, but $1.1 \mathrm{~m}$ at Exmouth, with slight increase for the long-term (2070-2100)

- The joint wave and surge distributions indicate a strong correlation between waves and surge at both Plymouth and Exmouth.

- There are clear evidences that storm conditions have caused significant damages to the coastal structures and shoreline changes.

- Model results for A1B scenario indicate an increase of wave height at both Plymouth and Exmouth for the short-term (2010-2040), and slight reduction for mid-term (2040-2070) and recovery for the long-term (2070-2100). Insignificant changes in the joint wave and surge distribution are found.

\section{ACKNOWLEDGMENTS}

The authors acknowledge the support of the European Commission through FP7, 2009-1, Contract 244104 - THESEUS ("Innovative technologies for safer European coasts in a changing climate"). Also the authors were supported through the iCOASST project funded via the UK Natural Environment Research Council grant No. NE/J005606/1.

\section{REFERENCES}

Chen, Y., S. Pan, R. Hewston and I. Cluckie. 2010. Ensemble modelling of tides, surge and waves. Proceedings of the $20^{\text {th }}$ International Offshore (Ocean) and Polar Engineering Conference, 828833.

Efron, B. 1979. Bootstrap methods: another look at the jackknife, Annals of Statistics, 7, 1-26.

Flather, R.A. 1981. Results from a model of the north east Atlantic relating to the Norwegian coastal current. In: Saetre, R., Mork, M. (Eds.), The Norwegian Coastal Current, Proceedings of the Norwegian Coastal Current Symposium, University of Bergen, 427- 458. 
Günther, H., S. Hasselmann and P.A.E.M. Janssen. 1992. The WAM model Cycle 4 (revised version), Technical Report No. 4, German Climate Centre, Hamburg.

Holt, J.T. and D.J. James. 2001. An s-coordinate density evolving model of the northwest European continental shelf: 1, Model description and density structure, Journal of Geophysical Research, $106,14015-14034$.

IPCC AR4. 2007. Climate change 2007. Fourth Assessment Report of the Intergovernmental Panel on Climate Change, Cambridge University Press, Cambridge, UK.

Li,Y., D. J. Simmonds, and D.E. Reeve. 2008. Quantifying uncertainty in extreme values of design parameters with resampling techniques, Ocean Engineering, 35(10), 1029-1038.

Monbaliu J., R. Padilla-Hernández, J.C. Hargreaves, J.C. Carretero-Albiach, W. Luo, M. Sclavo, H. Günther. 2000. The spectral wave model WAM adapted for applications with high spatial resolution, Coastal Engineering, 41, 41-62.

Osuna, P, J. Wolf, and M. Ashworth. 2004. Implementation of a wave-current interaction module for the POLCOMS system. Internal Document No. 168. Proudman Oceanographic Laboratory, Liverpool, UK.

Pan, S., Y. Chen, Y. Du, S. Reed and J. Wolf. 2009a. Modelling of sediment transport at Exe Estuary, Devon, UK, Proceedings of Coastal Dynamics 2009, CD-ROM.

Pan, S., Y. Chen, J. Wolf and Y. Du. 2009b. Modelling of waves in the Irish Sea: effects of oceanic wave and wind forcing, Ocean Dynamics, 59 (6), 827-836.

Reeve, D.E. 1996. Estimation of extreme Indian monsoon rainfall, International Journal of Climatology, 16 (1), 105-112.

WDCC. 2009. World Data Centre for Climate, CERA-DB. [http://cera-www.dkrz.de/].

Wolf, J., S.L. Wakelin and J.T. Holt. 2002. A coupled model of waves and currents in the Irish Sea, Proceedings of the 12th International Offshore and Polar Engineering Conference, 3, 108-114. 